\title{
Implementing a multi-sectoral HIV prevention program: Insights from the DREAMS Implementation Science research portfolio
}

\author{
Sanyukta Mathur \\ Population Council \\ Jerry Okal \\ Population Council \\ Julie Pulerwitz \\ Population Council
}

Follow this and additional works at: https://knowledgecommons.popcouncil.org/departments_sbsr-hiv How does access to this work benefit you? Let us know!

\section{Recommended Citation}

Mathur, Sanyukta, Jerry Okoth Okal, and Julie Pulerwitz. 2020. "Implementing a multi-sectoral HIV prevention program: Insights from the DREAMS Implementation Science research portfolio," Presentation at the PEPFAR DREAMS Annual Meeting, 4 December. 


\section{POPULATION COUNCIL}

Ideas. Evidence. Impact.

\section{IMPLEMENTING A MULTI-SECTORAL HIV PREVENTION PROGRAM}

Insights from the DREAMS Implementation Science Research Portfolio

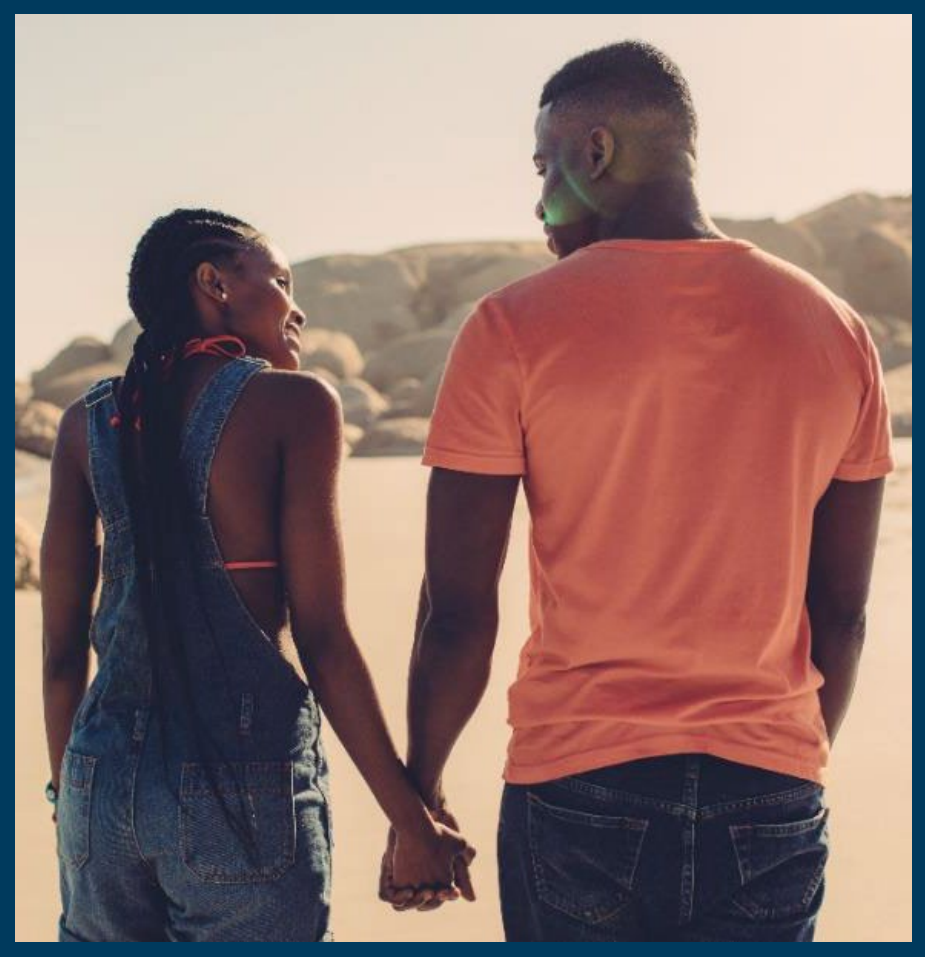

Sanyukta Mathur, DrPH MHS, Jerry Okal, PhD, \& Julie Pulerwitz, ScD 


\section{DREAMS Implementation Science Research}

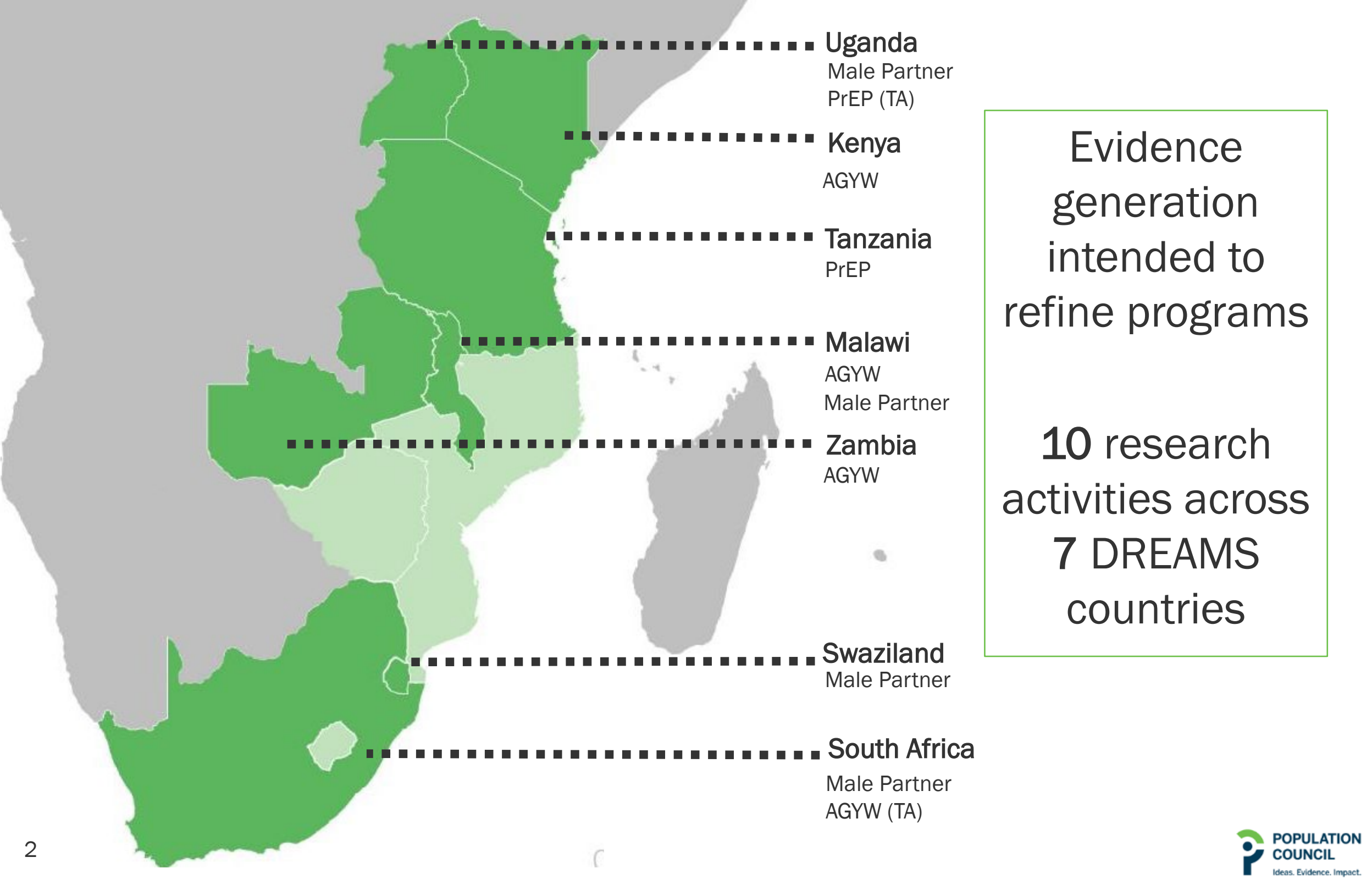




\section{Suite of tools and resources to strengthen capacity for AGYW programming}

- Building Girls' Protective Assets: A Collection of Tools for Program Design

- The Girl Roster ${ }^{\mathrm{TM}}$ : A Practical Tool for Strengthening Girl-Centered Programming

- Making the Most of Mentors: Recruitment, Training, and Support of Mentors for Adolescent Girl Programming-Toolkit

- More Than a Backdrop: Understanding the Role of Communities in Programming for Adolescent GirlsAction Guide

- Building Evidence to Guide PrEP Introduction for Adolescent Girls and Young Women

- It's All One Curriculum: Guidelines and Activities for a Unified Approach to Sexuality, Gender, HIV, and Human Rights Education

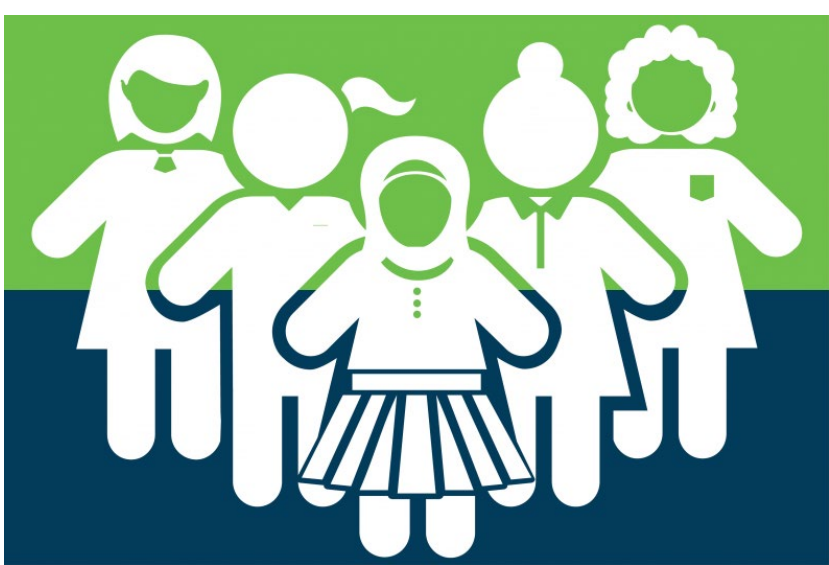

https://www.popcouncil.org/girl-centeredprogram-resources

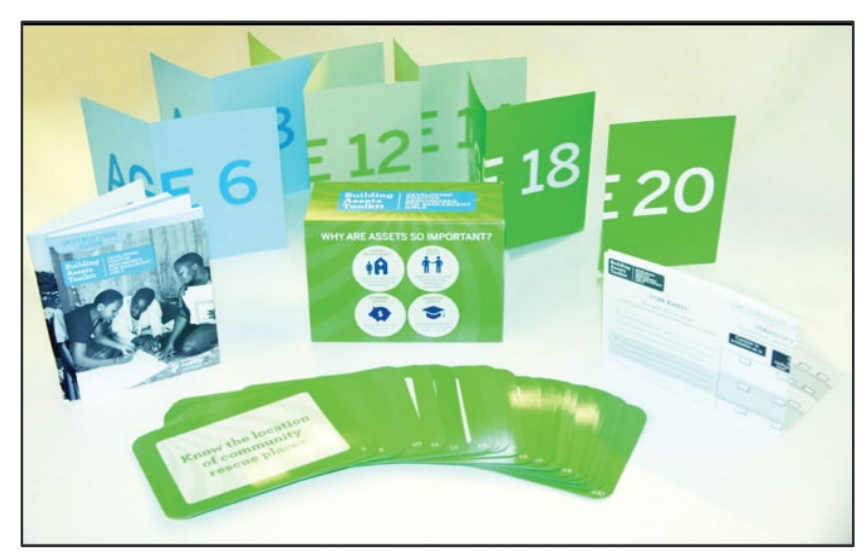




\section{Engaging AGYW}


AGYW's motivations for program engagement differ by age group

- AG more receptive to knowledge, skills, and building social networks

- YW keen to access skills, training, and tangible resources or options to enhance their livelihoods

In my opinion, I feel that for the people to be motivated, we should be providing [them] with money to start a business....At the moment, the people are demotivated...and we don't know ways which can encourage them....

- DREAMS implementing partner, Malawi 


\section{Strategies for engaging AGYW}

Initiating engagement

- Community leaders helped identify the most vulnerable girls

- Household visits gained trust/approval of family members and informed AGYW about DREAMS
Sustaining engagement

- Personal, confidential nature of relationship with mentors

- Provision of material support

- Provided social opportunities for youth to engage (e.g., sport activities) 


\section{Mentors were key to program implementation}

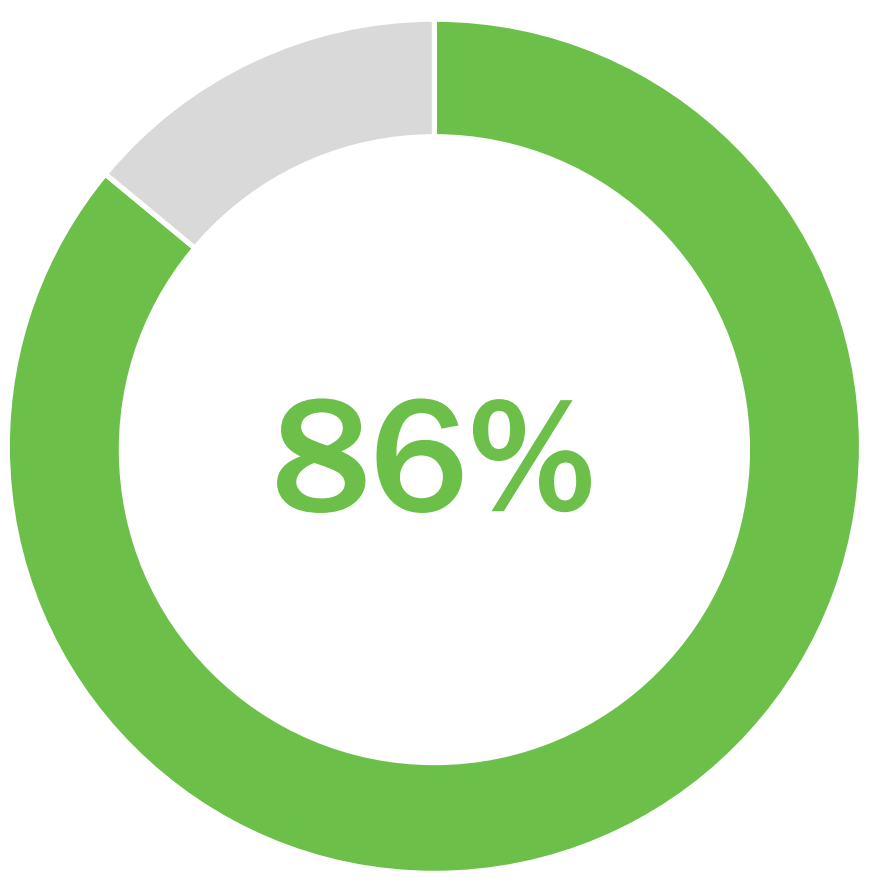

Felt comfortable seeking advice or referral from mentor
They could come and ask if there is any problem that they have. They are free to come so I feel like there is that relationship between me and the AGYWs because I am very open to every AGYW I have in my safe space. So I like it. It is like my family has grown bigger now.

\section{-Mentor, Zambia}




\section{Mentor challenges and support needed to address them}

Challenges Experienced

Doubts from community members about ability to teach/lead sessions

Limited material support \& logistical challenges

\section{Support Needed}

Desire for additional training and workshops to reinforce/practice skills (e.g., GBV, PrEP, HIV prevention, skillful parenting)

Salary or increased monetary support (e.g., increased stipend, airtime, transportation), and adequate materials (e.g., curriculum materials) and supplies (e.g., condoms)

Assistance in gaining program buy-in from parents and partners of AGYW, and local/village leadership to increase and retain AGWY participation 


\section{Educational support \& economic intervention helped retain AGYW in programming}

I do feel it has changed the lives of other girls...it has changed them because some of them have got school fees that they can pay and... The DREAMS have also cared for them very well....

- AG, Kenya

DREAMS has changed the lives of other girls and in community. ...They have created different programs that keep young women busy like they have opened salon, barber shop, tailoring, and computer courses too .... 


\section{Program implementers need support too}

- Tools to map AGYW in program community, and assess community resources that AGYW have access to

- Tools to strengthen skills/capacities of program mentors

- Training and partnerships to strengthen non-health components of the program

- Identify male partners of AGYW

- Use of program data to assess program effects 


\section{Implementers need new systems of communication, coordination, and management across organizations}

At the beginning everyone was trying to figure out how you put the pieces together. Everyone was running with their own targets, but I think even at the community level, there were different partners implementing DREAMS, so sometimes the schools were confused....

- DREAMS implementer, Zambia 


\section{HIV risk reduction}




\section{Need to sustain}

significant

improvements

in HIV

knowledge,

self-efficacy, \&

HIV testing

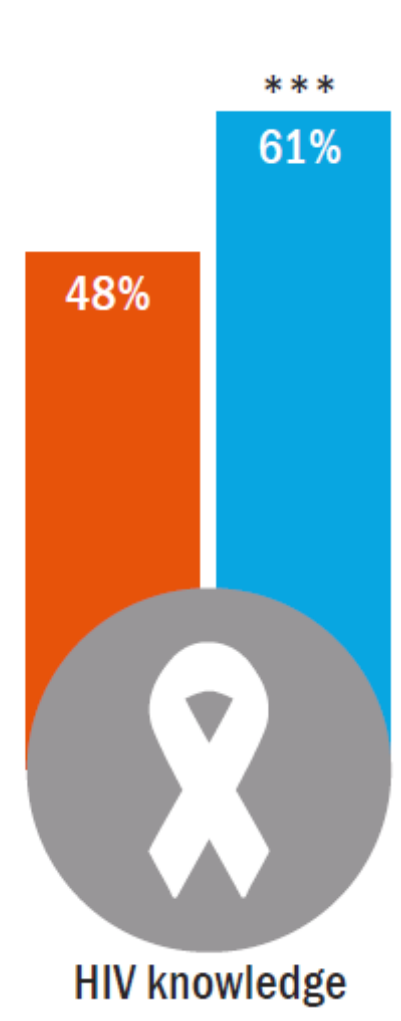

$* * * \mathrm{p}<0.001$

Note: similar results in Kenya and Zambia

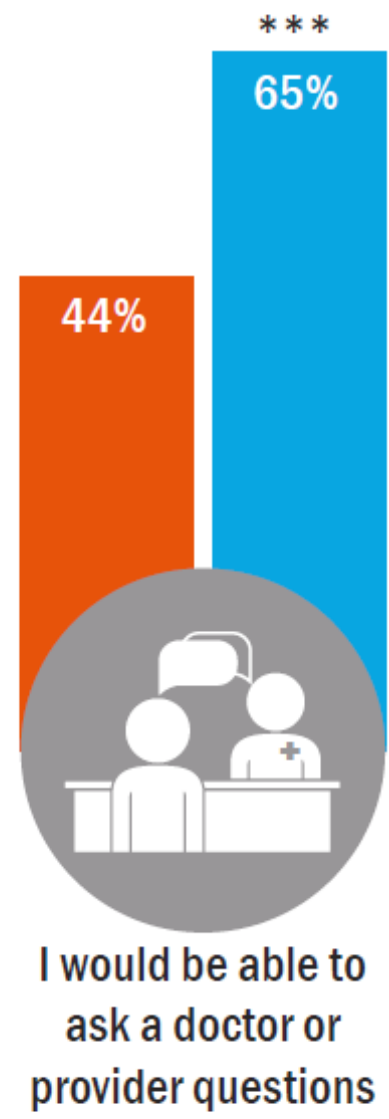

$83 \%$

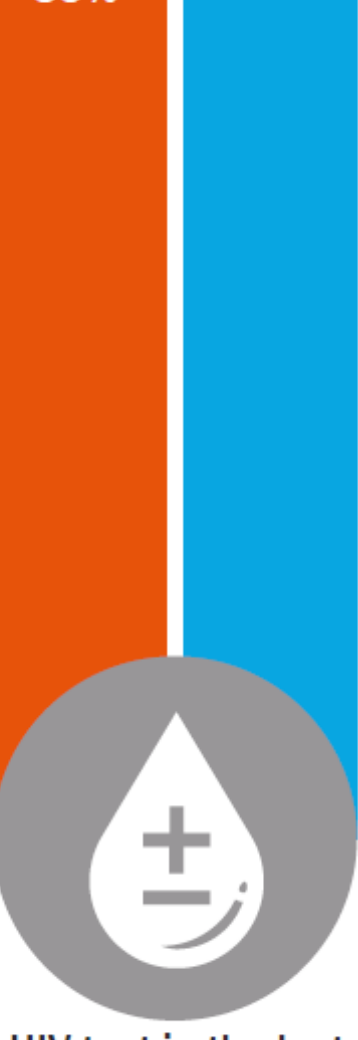

HIV test in the last 12 months 


\section{Need to redouble efforts on supporting HIV risk avoidance during key life transitions}

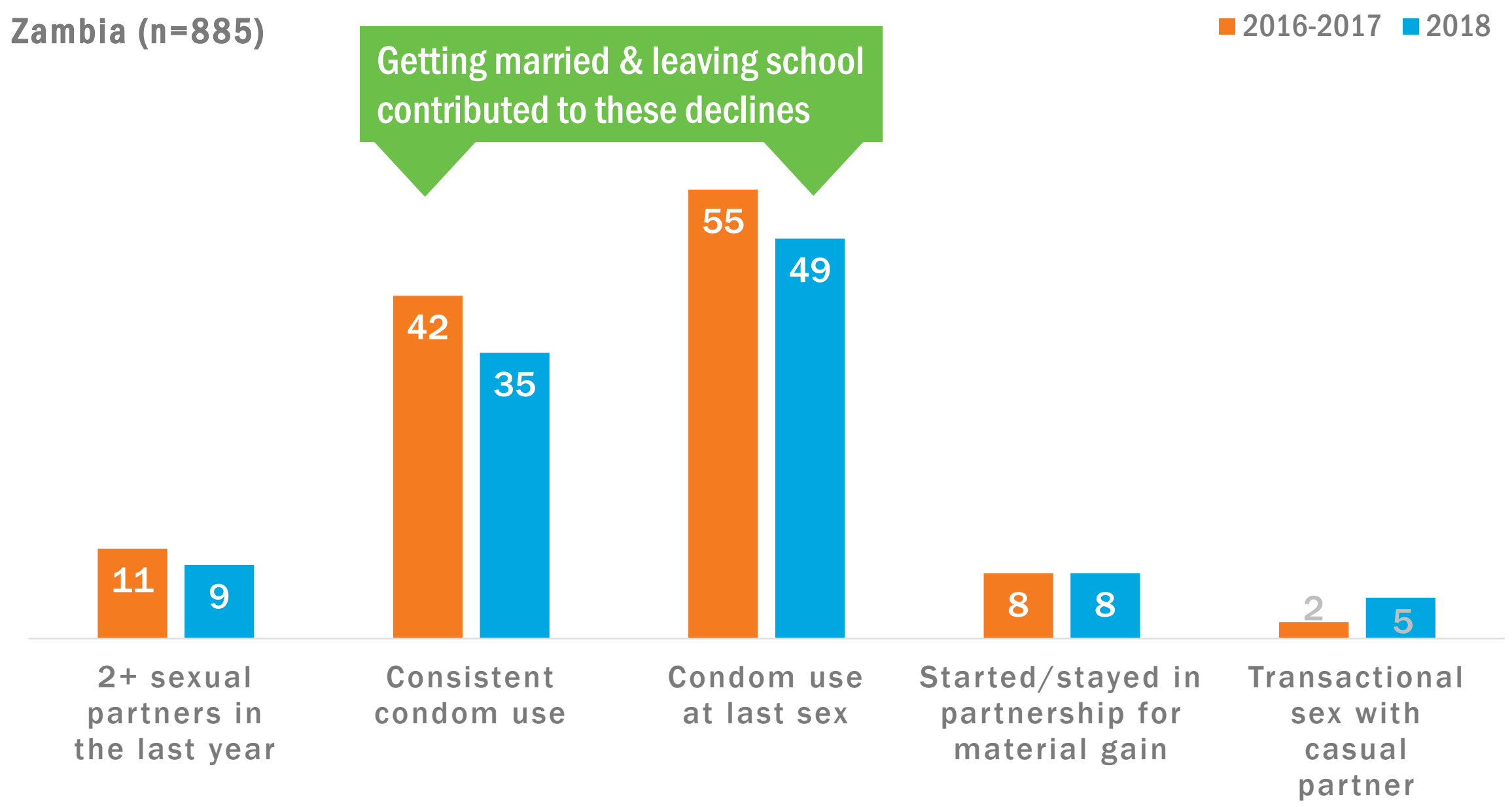




\section{What pathways reduced likelihood of transactional sex?}

AG who completed the social asset building curriculum \& received educational support

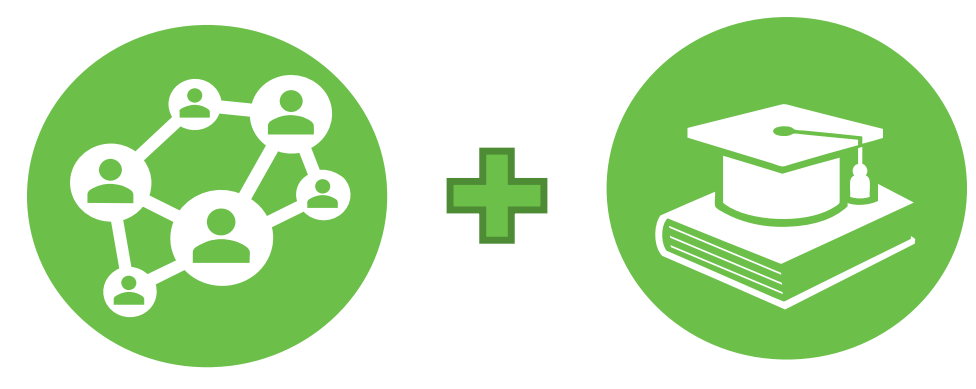

YW who completed social asset building curriculum, received YFHS, \& educational support, if no

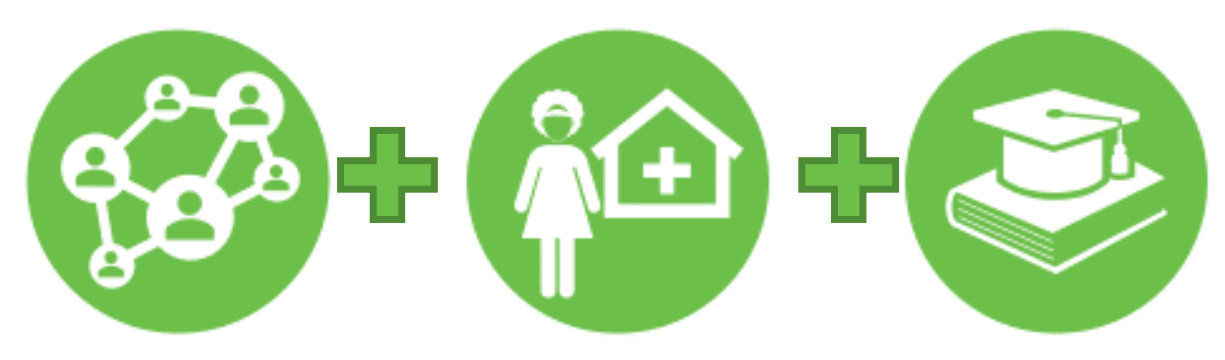
economic support 


\section{Improvements in HIV testing among men, especially among highest risk profiles}

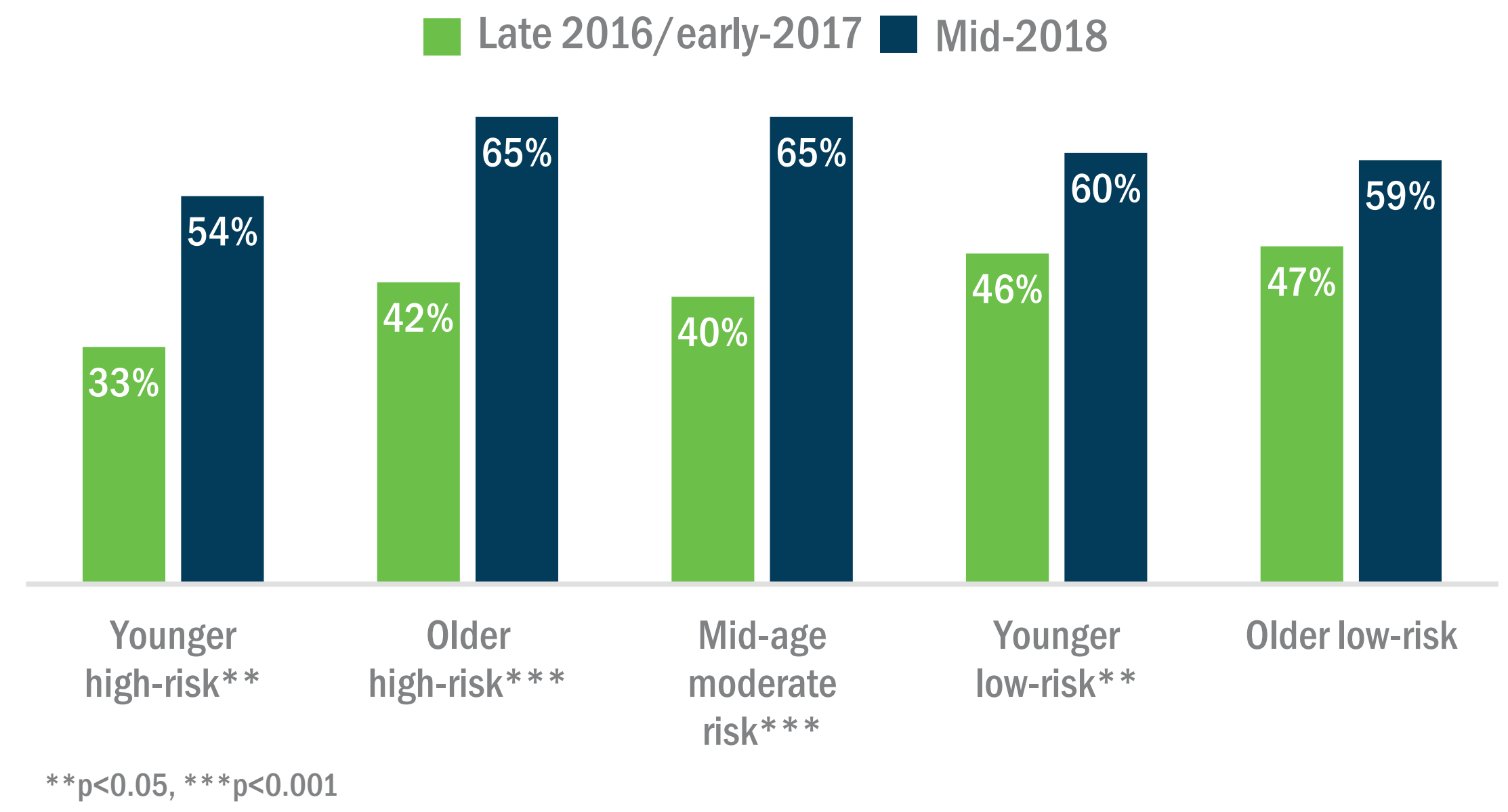

Study site: Eswatini, $n=1,391$ men ages 20-34 across all DREAMS Tinkhundla 
PrEP for AGYW 


\section{Clear recognition that social and gender norms increase HIV risk for AGYW}
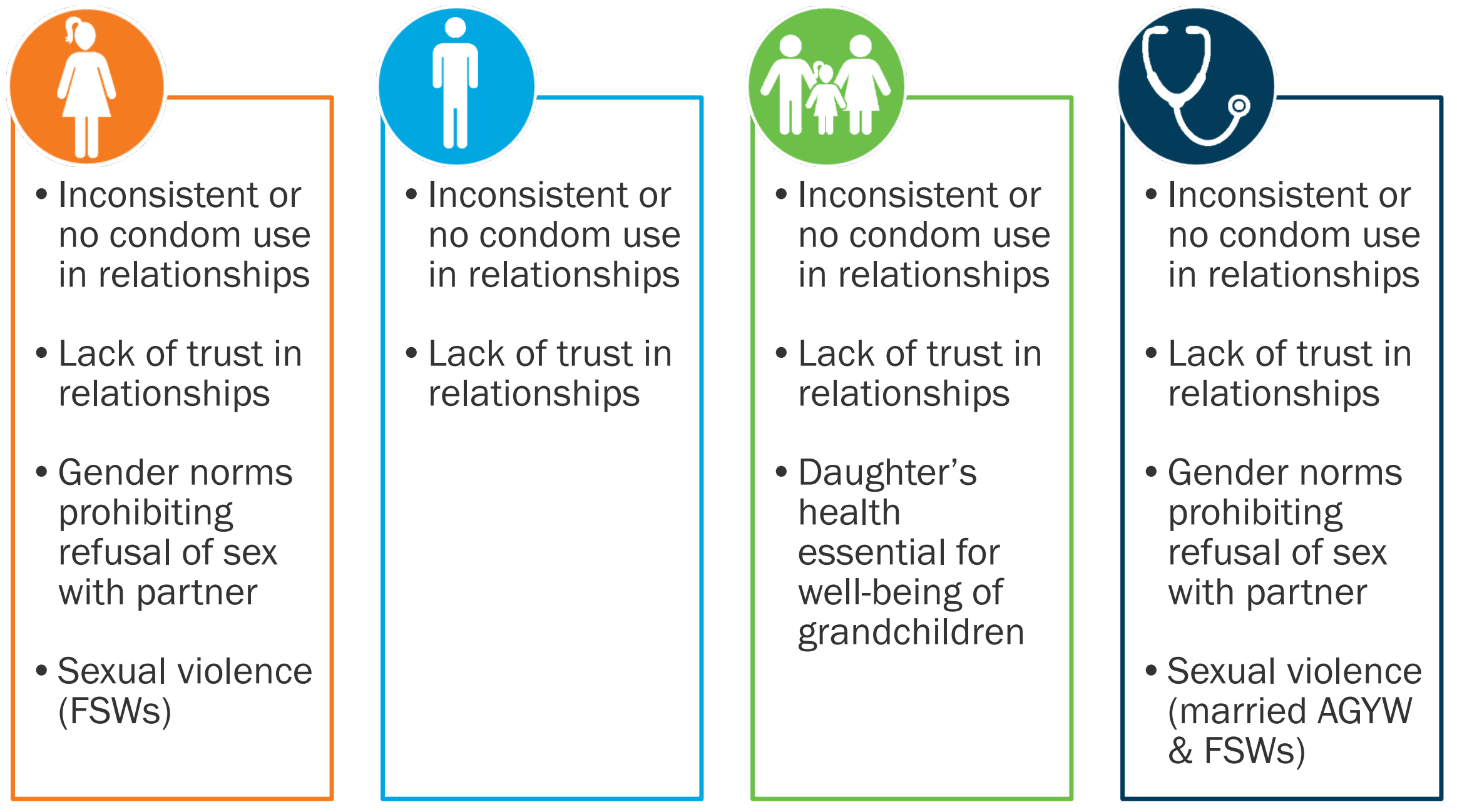


\section{Most AGYW were eligible for PrEP}

Adolescent girls $(\mathrm{n}=154) \quad$ Young women $(\mathrm{n}=289)$

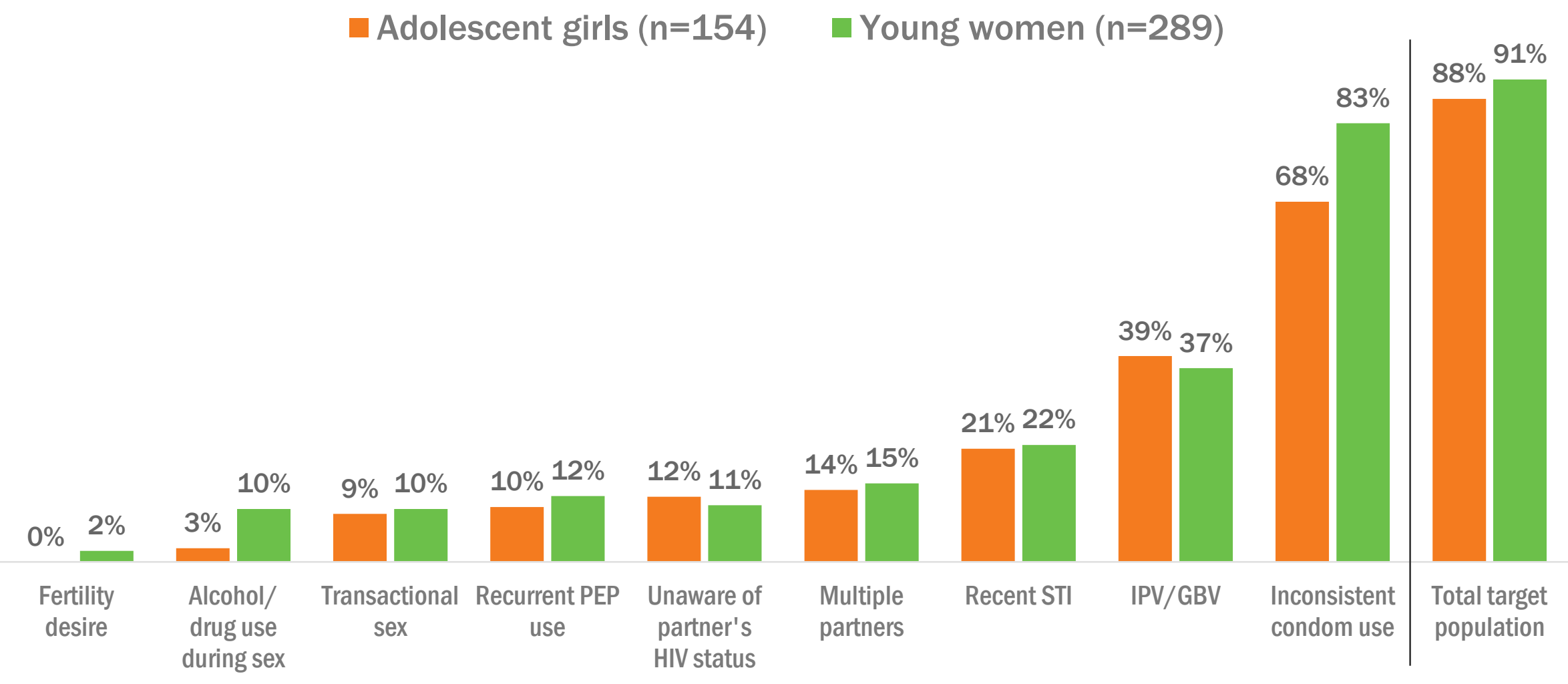




\section{More AGYW need access to PrEP}



135

$25.2 \% * *$

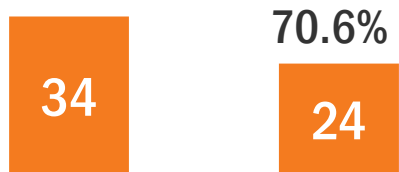

Total target Provider population interaction re: PrEP

$* * \mathrm{p}<0.01$

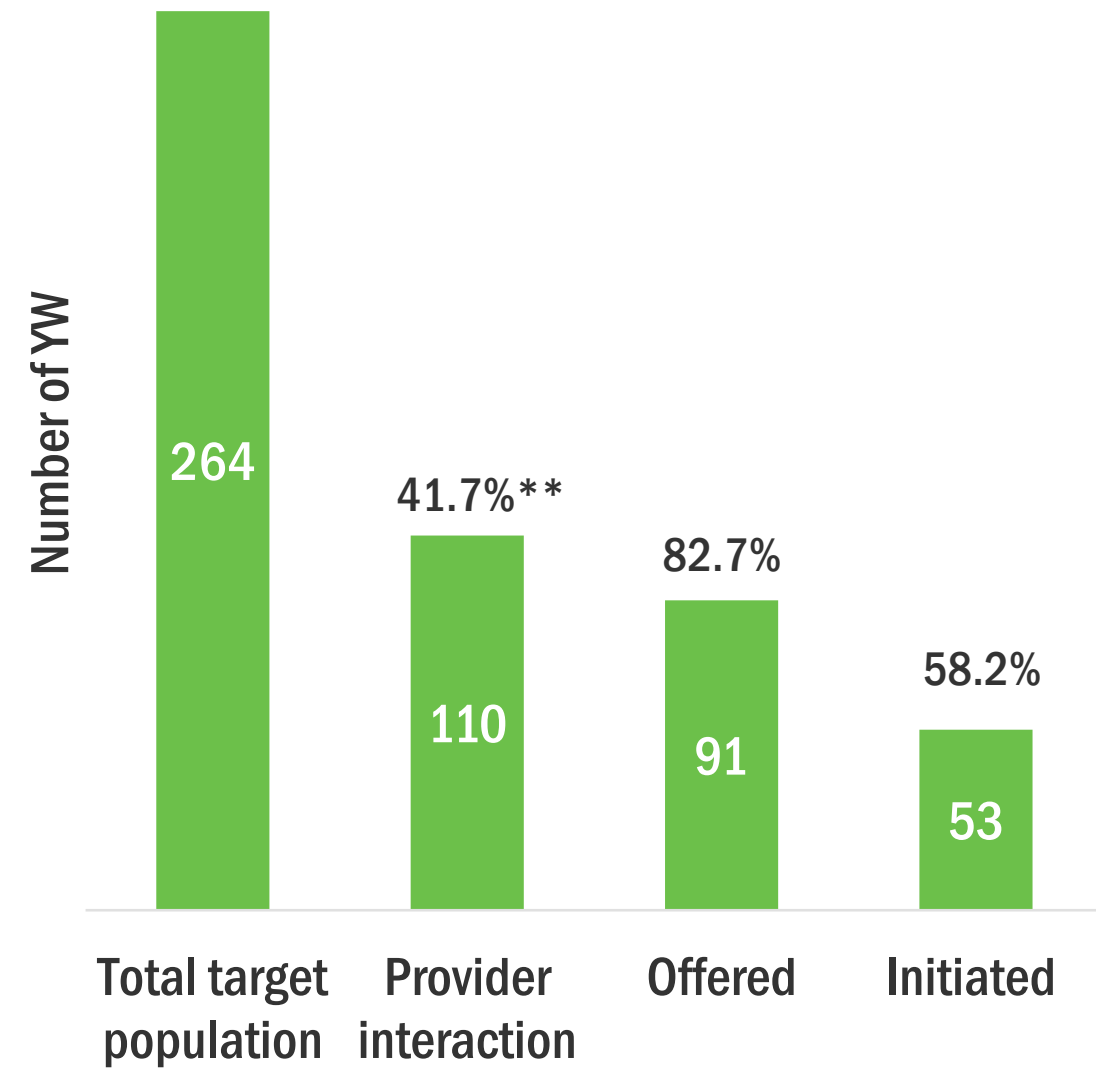

population interaction 


\section{Providers want training and integration of PrEP into non-HIV health services}

Factors associated with providers' willingness to prescribe PrEP $(n=316)$

\begin{tabular}{|ll|}
\hline Sufficiently trained to provide HIV services & Adj. IRR 1 (95\% CI) \\
\hline Patient-centered care & $1.13(1.02-1.24) *$ \\
\hline
\end{tabular}

${ }^{1}$ Adjusted for provider demographics, prior PrEP knowledge, other facility factors (e.g., stockouts) ${ }^{+} p<0.10 ;{ }^{*} p<0.05$

- Wanted job aids on youth-friendly care, HIV services, and PrEP, tools to identify who needs PrEP, and IEC materials in local languages

- Suggested providing PrEP in multiple settings, through different types of providers, and within various existing health programs 


\section{Young women's experiences with}

\section{PrEP use}

\section{Facilitators of PrEP use}

- Efficacy of PrEP for HIV risk reduction

- Control and agency over own HIV risk

- Social support from peers and parents

- Access to PrEP and supportive counseling

- Access to health care services for personal well-being

Study site: Uganda ( $\mathrm{n}=55$ YW FSWs)

\section{Barriers to PrEP use}

- Pill attributes and dosing regimen

- Side effects \& impact on livelihood

- Life transitions and shifting perceptions of HIV risk

- Mobility

- Marriage

- Change in livelihood

- Disclosure and social implications of use

- HIV-related stigma

- Relationship conflict 


\section{Anticipated HIV-related stigma}

When the peers of my age see a person taking PrEP, they will think that the person has AIDS, or they are very unfaithful hanging out with many partners. They will speak many things and I will be considered as a bad person in the community, a misbehaving person.

The bad thing about PrEP, it is embarrassing to swallow when you are among people who do not know that it exists because the majority know that the tablets are for people who have the [HIV] virus. 


\section{Relationship conflict}

- Covert PrEP use by AGYW could seed mistrust within the relationship

Our relationship will be affected if he is not informed, but if I briefly explain it to him, he will understand I am using PrEP so as to protect myself from HIV infections... if he understands me properly, he can decide to accompany me and begin to take PrEP as well. But if I don't tell him and he finds them on his own, that is where the problem steps in. ...he [partner] came across those drugs, and he got out of control... when he found the drugs he became disturbed, furious, threw them, asked me whether a I am a commercial sex worker, whether am infected, if I had infected him. I told him the drugs are not for HIV, fearing to explain further, he would discover what I used to do.... he saw them and became furious. He poured them. He beat me to tell him the truth... He beat me and we seriously fought....

\section{-YW, PrEP user (8mo), Uganda}




\section{PrEP provision requires multi-level considerations}

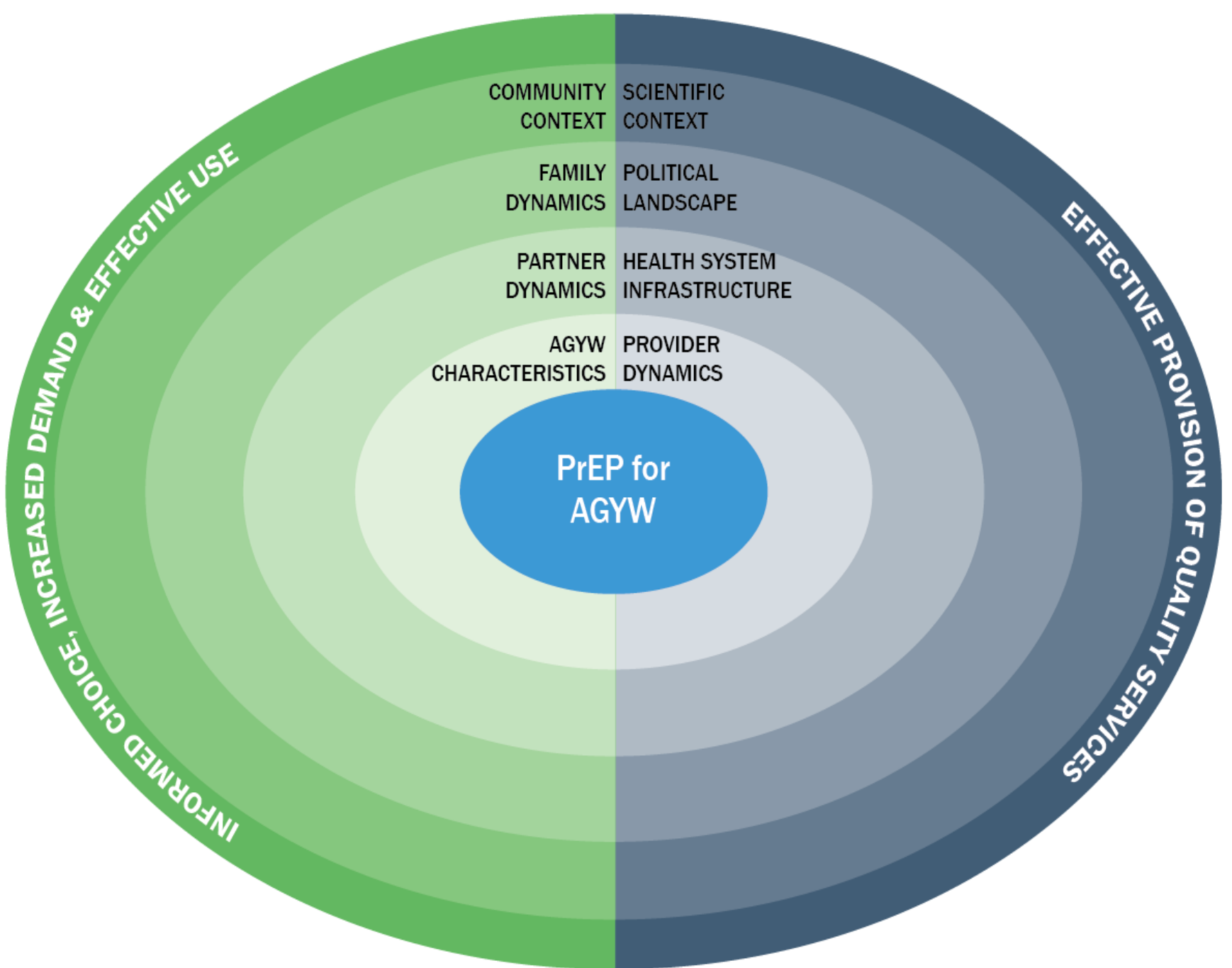




\section{Addressing gender dynamics/norms}




\section{HIV risk, relationship power \& violence}

Having relationship power strongly associated with:

$\checkmark$ Less sexual/physical violence

$\checkmark$ More condom use at last sex

$\checkmark$ More knowledge of partner's HIV status
Sexual violence experience in the last 12 months

$1.9 \%$ From partners $(n=597)$

$21 \%$ From non-intimate

partners $(n=1,778)$

\section{AGYW who experienced sexual violence were $2 x$ as likely to report an STI symptom, and anxiety and depression}




\section{Some decreases in violence seen}

\begin{tabular}{|c|c|c|}
\hline \multirow{2}{*}{ Experience of violence in the past year } & \multicolumn{2}{|c|}{$\begin{array}{c}\text { Kenya } \\
(n=736)\end{array}$} \\
\hline & $\begin{array}{c}\text { Round } 1 \\
\%\end{array}$ & $\begin{array}{c}\text { Round } 2 \\
\%\end{array}$ \\
\hline \multicolumn{3}{|l|}{ Among sexually active } \\
\hline Sexual violence from partners & 20 & $9^{\star \star \star}$ \\
\hline \multicolumn{3}{|l|}{ Among all AGYW } \\
\hline Sexual violence from non-partners & 26 & $17^{* \star *}$ \\
\hline
\end{tabular}

- Regressions confirm that AGYW were less likely to experience sexual violence from partners (Adj. IRR 0.43 (0.31-0.59)) and from non-partners (0.65 (0.53-0.81)) over time

- Similar results in Zambia and Malawi

$* * * p<0.001$, Regression models adjusted for age, current schooling, marital status, orphanhood status, continuity of program exposure, and site-level clustering 


\section{Levels of empowerment can differ across AGYW age groups}
-15-17 years $\square 18-20$ years $\square 21-24$ years $(n=1,101)$

My partner has more say than I do about important decisions that affect us*

If my partner wants to have sex, he would expect me to agree*
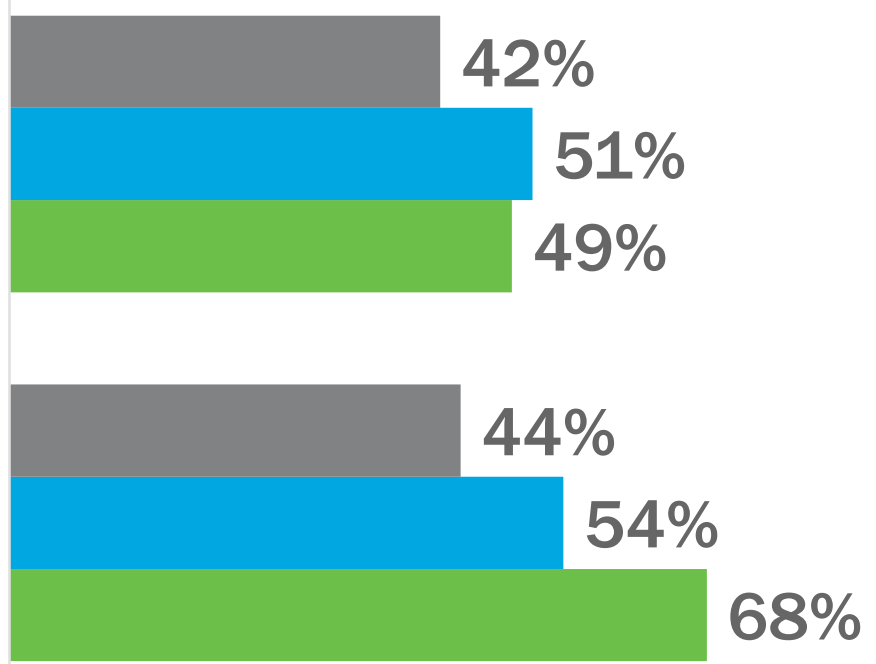

When partner and I disagree, he gets his way most of the time*

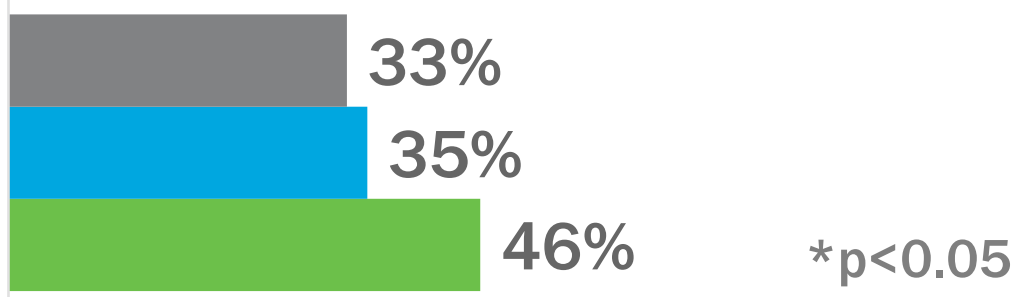




\section{Financial autonomy can support empowerment, but only for some}

- Financial independence can afford power to reject unwanted or violent relationships

- Women's agency greater in nonmarital vs. marital relationships

- Despite more support for joint household decision-making, married women's agency still heavily influenced by cultural/

When you use his money, you would feel guilt and fail to refuse when he asks for sex.

-20-year-old single student religious norms of male dominance 


\section{Male partners of DREAMS AGYW described benefits}

- Learning about social/gender norms from partners, and own direct participation

- Commonly cited impacts included:

- Improved couple communication \& conflict resolution

- Reducing/eliminating side partners

- More impetus to link to HIV services

\section{[We] now know how to} communicate with each other... we no longer have arguments over simple things....

-Male partner, Mukono
The meeting taught me, as a person, to be safe, and practice self-control.... Have one partner [and] stop admiring other women....

-Male partner, Sembabule 


\section{Many DREAMS implementing partners organically incorporated men}

...we mobilize men to receive HTC... after that, they are given information on VMMC. But we have encouraged [our CBOs] to engage men further...[for example] we trained some men as male peers in Stepping Stones, to be able to do behavior change among men.

-Implementing partner, Mukono, Uganda 


\section{USAID IGWG resource for engaging men \& boys...}

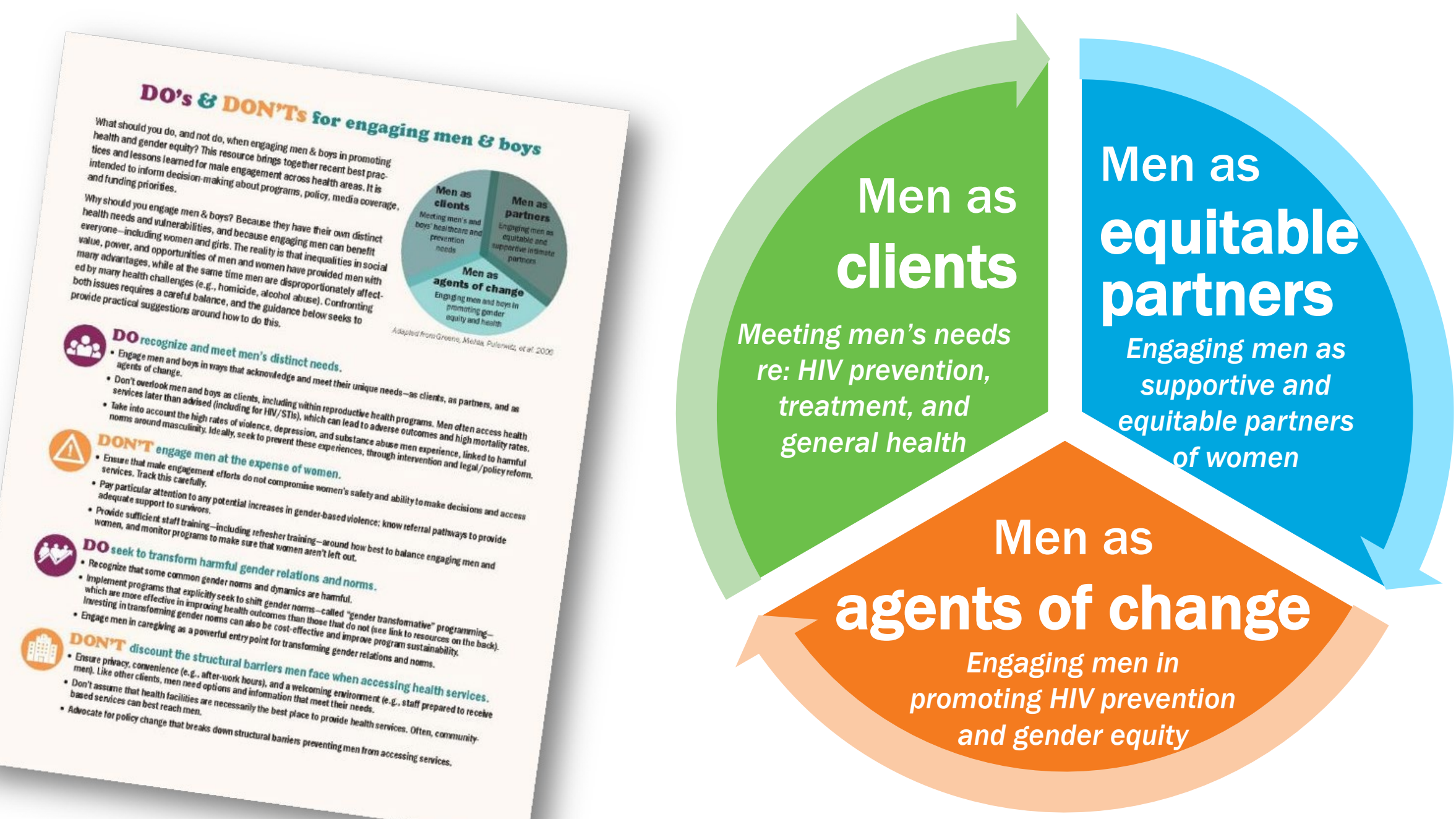

Pulerwitz J., A. Gottert, M. Betron, and D. Shattuck on behalf of the Male Engagement Task Force, USAID Interagency 
DO recognize and meet men's distinct needs.

DON'T engage men at the expense of women.

DO seek to transform harmful gender relations and norms.

DON"T discount the structural barriers men face when accessing health services.

\section{(19.} DO gather evidence with men and boys (and not just women and girls).
DON'T start with the assumption that all men are bad actors.

DO start early in the life course.

DON'T overlook the diversity of men and boys in the population.
E.

.
DO engage men on their own and in groups of men, as well as together with women.

DON'T overlook scale and sustainability for achieving impact. 


\section{Where do we go from here?}

1. Collective action to sustain emphasis on comprehensive HIV prevention among AGYW

2. Leverage sectoral efforts to address the intersecting factors that influence HIV vulnerability for AGYW

3. Support AGYW to lower HIV risk during key life transitions

4. Support program implementers to reach the "right" AGYW with the "right" programming

5. Engage the "right" men, as clients, as partners, and advocates in HIV prevention efforts

6. Generate evidence to appropriately adapt programs to other settings and monitor sustainability (of outcomes and structures) over time

7. Examine influence of Covid-19 and risk mitigation measures on AGYW health and well-being 


\section{Experiences during Covid-19}

Phone survey was completed with 603 10- to 19-year-old adolescents in Kisumu, Kenya; $\mathrm{HH}$ were part of the DREAMS program communities

- AG spending more time on household chores

- Schooling/learning ongoing for most, but impacted due to limited lessons and access challenges

- $47 \%$ skipping meals/food insecurity increased

- $47 \%$ report increased feelings of depression and hopelessness

- 54\% had difficulty in acquiring sanitary use products

- $13 \%$ had experienced physical abuse in the last month

Population Council. (2020) "Social, health, education and economic effects of COVID-19 on adolescent girls in Kenya: Responses from the first round of adolescent data collection, August 2020-Kisumu," COVID-19 Research \& Evaluations brief. Nairobi: Population Council. 


\section{Acknowledgements}

- Population Council: Sanyukta Mathur, Ann Gottert, Julie Pulerwitz, Miriam Temin, Jerry Okal, Maurice Musheke, Nanlesta Pilgrim, Nrupa Jani, Craig J. Heck, Tracy McClair, Sangram K. Patel, Bidhubhushan Mahapatra, Monika Walia, Louis Apicella, Mike Mbizvo, James Matheka, Drosin Mulenga, Lyson Tenthani, John Mark Wiginton, Cristian Valenzuela, Pamela Keilig

- Kenya \& Zambia: Collaboration with DREAMS implementing partners (PATH/Aphia Plus, PACT) \& Iocal USAID and PEPFAR DREAMS teams

- Malawi: Local implementing partner-COM, Effie Chipeta, Victor Mwapasa, Wanangwa Chimwaza \& Collaboration with USAID/Malawi and DREAMS implementing partners

- Tanzania: Local implementing partner-CSK (Catherine Kahabuka), Neema Makyao (NACP, Tanzania) \& collaboration with NACP/MOH and local USAID and PEPFAR DREAMS teams

- South Africa: Local research partner-Epicentre: Cherie Cawood, \& collaboration with: South African DOH, SANAC, eThekwini Municipality, PEPFAR-South Africa, DREAMS implementing partners

- Eswatini: Local research partner \& investigators-Institute for Health Measurement (IHM): Patrick Shabangu, Kelvin Sikwibele, Muhle Dlamini (SNAP), Muziwethu Nkhambule (NERCHA); \& collaboration with Ministry of Health, NERCHA, SNAP, PEPFAR-Eswatini, DREAMS implementing partners

- $\quad$ Uganda: Local research partner-Makerere University, Child Health and Development Centre (CHDC): Godfrey Siu, Anne Katahoire, \& Collaboration with: Makerere University Walter Reed Project, Kampala, Uganda, U.S. Army Medical Research Directorate-Africa, Kampala, Uganda U.S. Military HIV Research Program, Walter Reed Army Institute of Research, Henry M. Jackson Foundation for the Advancement of Military Medicine, Ministry of Health, District local government, PEPFAR-Uganda, DREAMS implementing partners

Funding support from the Bill \& Melinda Gates Foundation and Project SOAR/PEFAR \& USAID (Malawi) 


\section{POPULATION}

COUNCIL

Ideas. Evidence. Impact.

(C) 2020 The Population Council. All rights reserved.

Use of these materials is permitted only for noncommercial purposes. The following full source citation must be included:

Mathur, Sanyukta, Jerry Okal, and Julie Pulerwitz. 2020. “Implementing a multisectoral HIV prevention program: Insights from the DREAMS implementation science research portfolio," presented at PEPFAR DREAMS Annual Meeting,

14 December.

This presentation may contain materials owned by others. User is responsible for obtaining permissions for use from third parties as needed. 